\title{
PENERAPAN APLIKASI NIFASKU BERPENGARUH TERHADAP PENGETAHUAN IBU MENGENAI PERAWATAN MASA NIFAS DAN BAYI BARU LAHIR
}

\author{
Dewi Nurdianti ${ }^{1 *}$, Ade Kurniawati ${ }^{2}$, Nadia Qurota ${ }^{3}$, Resa Oktavia ${ }^{4}$ \\ 1,2,3,4Prodi DIII Kebidanan Universitas Muhammadiyah Tasikmalaya \\ *Korespondensi Email : dewi.nurdianti@umtas.ac.id
}

\section{ABSTRACT APPLICATION OF MY PARTNERSHIP APPLICATION INFLUENCE ON MOTHER'S KNOWLEDGE ABOUT PUBLIC CARE AND NEWBORN BABY}

Background: Knowledge of postpartum and newborn care is very important that every pregnant woman should know before giving birth. This information is to improve the quality of postpartum mothers. Information technology from smartphones using Android-based applications can be used to increase mother's knowledge about postpartum and newborn care.

Purpose: The purpose of this study was to analyze the effect of the application of my parturition on the knowledge of pregnant women TM III regarding postpartum and newborn care in the work area of the Kersanegara Public Health Center, Tasikmalaya City 2020.

Methods: The method used is a quasi-experimental with the type of One Group Pretest-Postest. The population in this study were 3rd trimester pregnant women who met the inclusion criteria. The sample of this research is pregnant women obtained by purposive sampling technique with a total of 30 people. Data analysis using T-test

Results: The results showed an increase knowlegde after the study was 12.2 (7.28), $p$ value 0.000 ( $\alpha=$ $0.005)$.

Conclusion:. Aplikasi Nifasku has an effect on increasing mother's knowledge regarding postpartum care and newborns

Suggestion: Knowledge of postpartum and newborn care must continue to be improved by utilizing various media, one of which is by utilizing other information, one of which is the Aplikasi Nifasku

Keywords: Aplikasi Nifasku ,Knowledge postpartum and newborn care.

\section{ABSTRAK}

Latar Belakang : Pengetahuan perawatan masa nifas dan bayi baru lahir merupakan hal sangat penting yang harus di ketahui oleh setiap ibu hamil menjelang persalinan . Informasi ini untuk meningkatkan kualitas ibu paska melahirkan. Teknologi informasi dari smartphone dengan menggunakan aplikasi berbasis android dapat dimanfaatkan untuk meningkatkan pengetahuan ibu tentang perawatan masa nifas dan bayi baru lahir..

Tujuan : Tujuan penelitian ini untuk menganalisis pengaruh penerapan aplikasi nifasku terhadap pengetahuan ibu hamil TM III mengenai perawatan masa nifas dan bayi baru lahir di wilaya kerja Puskesmas Kersanegara Kota Tasikmalaya 2020.

Metode : Metode yang digunakan adalah quasi eksperimen dengan tipe One Group Pretest-Postest, Populasi pada penelitian ini adalah ibu hamil Trimester 3 yang memenuhi kriteria inklusi. Sampel penelitian ini adalah Ibu hamil yang diperoleh dengan teknik purposive sampling dengan jumlah 30 orang .Analisis data dengan menggunakan uji T-test.

Hasil : Hasil penelitian didapatkan peningkatan penegtahuan setelah penelitian adalah $12,2(7,28), p$ value $0,000(a=0,005)$

Kesimpulan : Aplikasi Nifasku berpengaruh Terhadap Peningkatan Pengetahuan Ibu Mengenai Perawatan Masa Nifas Dan Bayi Baru Lahir.

Saran : Pengetahuan perawatan masa nifas dan bayi baru lahir harus terus ditingkatakan dengan menanfaatkan berbagai media salah satunya dengan memanfaatkan informasi lain salah satunya aplikasi nifasku.

Kata Kunci :Aplikasi Nifasku, Pengetahuan, Perawatan Masa Nifas Dan Bayi baru lahir 


\section{JKM (Jurnal Kebidanan Malahayati),Vol 7,No.4.Oktober 2021, \\ ISSN (Print) 2476-8944 ISSN (Online) 2579-762X, Hal 780-784}

\section{PENDAHULUAN}

Asuhan pada periode setelah kelahiran sangat penting. Tidak hanya untuk keberlangsungan hidup saja, tetapi juga untuk masa depan ibu dan bayi yang baru lahir.Perubahan besar terjadi sealam periode ini yang menentukan kesejahteraan mereka dan potensi masa depan yang sehat.Sayangnya, sebagian ibu dan bayi baru lahir di negara-negara berepenghasilan rendah dan menengah tidak menerima asuhan yang optimal selama periode ini(Astuti, Judistiani, Rahmiati, \& Susanti, 2015)

Kurangnya pengetahuan ibu nifas tentang perawatan masa nifas dan neonatus disebabkan kurangnya pengalaman ibu dan kekhawatiran, hal ini disebabkan adaptasi psikologis ibu masa nifas,kelelahan membuat ibu cukup istirahat untuk mencegah gejala kurang tidur, seperti mudah tersinggung,terjadinya infeksi tali pusat pada bayi baru lahir, hal ini berdampak dari kurangnya pengetahuan dan keterampilan ibu (Norlina, 2017) .

Pengetahuan perawatan masa nifas dan bayi baru lahir merupakan hal sangat penting yang harus di ketahui oleh setiap ibu hamil menjelang persalinan, informasi ini penting untuk meningkatkan kualitas ibu paska melahirkan.Peningkatan pengetahuan ini dapat dilakukan dengan cara memberikan pendidikan kesehatan selama kehamilan. Penggunaan metode pendidikan kesehatan yang lebih inovatif di harapakan dapat meng efektifitas pendidikan kesehatan dalam meningkatakan pengetahuan (Nurhabibi, 2018).

Penerapan Teknologi Informasi Mobile Health (mHealth) dalam peningkatan pelayanan kesehatan pada ibu hamil merupakan salah satu solusi alternatif yang dapat dapat membantu dalam memberikan informasi dan edukasi kesehatan bagi ibu hamil, perwatan masa nifas, informasi perwatan bayi baru lahir tanpa dibatasi ruang dan waktu dan tanpa harus bertatap muka langsung dengan tenaga kesehatan khususnya bidan sebagai tonggak pemberi pelayanan yang paling banyak dikunjungi oleh ibu hamil(Ghanylsmaeel \& Khadhm Jabar, 2013).

Aplikasi smartphone memungkinkan bagi ibu untuk mengakses layanan kesehatan yang mereka butuhkan, membantu pertolongan pertama sekaligus menghubungi tenaga kesehatan dan membantu pengguna untuk menjawab keluhan seputar kehamilan dan perawatan masa nifas(Feroz, Perveen, \& Aftab, 2017)

Maka peneliti mencoba merancang "Aplikasi Nifasku". Aplikasi ini memanfaatkan teknologi smartphone berbasis android sebagai panduan yang lebih praktis yang dapat digunakan ibu hamil dalam memepersiapakan perwatan masa nifas dan bayi baru lahir.

\section{METODE PENELITIAN}

Metode yang digunakan adalah quasi eksperimen dengan tipe One Group PretestPostest, Populasi pada penelitian ini adalah ibu hamil Trimester 3.Sebelum menjadi responden penelitian ibu hamil telah mengisi surat persetujuan setelah penjelasan terlebih dahulu. Sampel penelitian ini adalah lbu hamil yang diperoleh dengan teknik purposive sampling dengan jumlah 30 orang .Analisis data dengan menggunakan uji Ttest.

\section{HASIL DAN PEMBAHASAN}

Penelitian ini dilaksanakan pada bulan November 2020 di Wilayah Kerja Puskesmas Kersanegara Kota Tasikmalaya Proses penelitian dilakukan dengan mengidentifikasi ibu hamil yang memenuhi kriteria inklusi sehingga didapatkan sebanyak 30 ibu hamil yang telah menandatangani lembar persetujuan subjek penelitian

Tabel 1

\section{Karakteristik Berdasarkan Pendidikan, Pekerjaan dan Paritas}

\begin{tabular}{|c|c|c|}
\hline Karakteristik & Frekuensi & Persentase \\
\hline \multicolumn{3}{|l|}{ Umur } \\
\hline$<20$ & 1 & 3,3 \\
\hline $20-35$ & 26 & 86,7 \\
\hline$>35$ & 3 & 10 \\
\hline \multicolumn{3}{|l|}{ Pendidikan } \\
\hline SD sederajat & 10 & 33,3 \\
\hline SMP Sederajat & 6 & 20,0 \\
\hline SMA Sederajat & 13 & 43,3 \\
\hline PT Sederajat & 1 & 3,3 \\
\hline \multicolumn{3}{|l|}{ Pekerjaan } \\
\hline Tidak Bekerja & 30 & 100 \\
\hline Bekerja & 0 & 0 \\
\hline \multicolumn{3}{|l|}{ Gravida } \\
\hline 1 & 10 & 33,3 \\
\hline 2 & 8 & 26,7 \\
\hline 3 & 7 & 23,3 \\
\hline 4 & 4 & 13,3 \\
\hline 5 & 1 & 3,3 \\
\hline Total & 30 & 100 \\
\hline
\end{tabular}

Berdasarkan tabel 1 karakteristik berdasarkan pendidikan ibu hamil paling banyak adalah SMA sederajat $(43,3 \%)$. Seluruh ibu hamil tidak bekerja $(100 \%)$ dan Jumlah kehamilan paling banyak merupakan kehamilan pertama $(33,3 \%)$. 
Tabel 2.

Data Pre Test Pengetahuan Ibu Mengenai Perawatan Masa Nifas Dan Bayi Baru Lahir

\begin{tabular}{ccccc}
\hline Pengetahuan Pre & Mean $(\mathbf{S d})$ & Median & Minimum & Maximum \\
\hline & $71,0(6,66)$ & 70,0 & 57 & 83 \\
\hline
\end{tabular}

Berdasarkan tabel 2 didapatkan gambaran pre tes pengetahuan ibu tentang perawatan masa nifas dan bayi baru lahir. Rata rata pengetahuan ibu adalah 71(6,66) dengan skor terendah 57 dan skor tertinggi 83.

Tabel 3.

Data Post Test Pengetahuan Ibu Mengenai Perawatan Masa Nifas Dan Bayi Baru Lahir Setelah Penelitian

\begin{tabular}{ccccc}
\hline Pengetahuan Post & Mean (Sd) & Median & Minimum & Maximum \\
\hline & $83,3(5,87)$ & 80,0 & 77 & 93 \\
\hline
\end{tabular}

Berdasarkan tabel 3 didapatkan gambaran post tes Rata rata pengetahuan ibu $83,3(5,87)$ dengan skor terendah 77 dan skor tertinggi 93

setelah intervensi aplikasi nifas.

Tabel 4.

Pengaruh Penerapan Aplikasi Nifasku Terhadap Peningkatan Pengetahuan Ibu Mengenai Perawatan Masa Nifas Dan Bayi Baru Lahir

\begin{tabular}{ccccc}
\hline Pengetahuan Pre \& & Paired Difference & P value & \multicolumn{2}{c}{$95 \%$ Confidence Interval } \\
\cline { 4 - 5 } Pengetahuan post & Mean(SD) & & lower & upper \\
\hline & $12,2(7,28)$ & 0,000 & 9,478 & 14,922 \\
\hline
\end{tabular}

Berdasarkan tabel 4 didapatkan peningkatan skor sebelum dan setelah penerapan pengaruh aplikasi nifasku adalah 12,2 (7,28). Hasil uji statistik menggunakan $T$ Dependent Test menunjukkan $p$ value $0,000(\alpha=0,005)$. Berdasarkan hasil pengujian hipotesis terdapat Pengaruh Penerapan Aplikasi Nifasku Terhadap Peningkatan Pengetahuan Ibu Mengenai Perawatan Masa Nifas Dan Bayi Baru Lahir.

\section{PEMBAHASAN}

Asuhan pada periode setelah kelahiran sangat penting. Tidak hanya untuk keberlangsungan hidup saja, tetapi juga untuk masa depan ibu dan bayi yang baru lahir.Perubahan besar terjadi sealam periode ini yang menentukan kesejahteraan mereka dan potensi masa depan yang sehat.Sayangnya, sebagian ibu dan bayi baru lahir di negara-negara berepenghasilan rendah dan menengah tidak menerima asuhan yang optimal selama periode(Astuti et al., 2015).

Periode post partum adalah periode segera setelah melahirkan yang dapat menimbulkan risiko kesehatan yang besar bagi ibu dan bayi baru lahir. Namun periode postpartum dan pasnanatal kurang mendapat perhatian dari penyedia layanan kesehatan sejak dari kehamilan dan
persalinan(WHO, 2015). SDKI tahun 2012 mencatat trend perawatan postnatal yang ada di Indonesia. Sebanyak $80 \%$ wanita menerima perawatan postnatal setelah proses persalinan mereka hingga dua hari pertama masa kritis setelah persalinan. Secara khusus, $56 \%$ wanita menerima perawatan postnatal kurang dari empat jam setelah melahirkan, $13 \%$ menerima perawatan postnatal dalam 4-23 jam, dan 11\% menerima perawatan 1-2 hari setelah persalinan. Satu dari sembilan perempuan tidak menerima pemeriksaan postnatal(SDKI, 2012).

Kesadaran akan pentingnya kesehatan pada masa nifas di Indonesia saat ini masih belum optimal karena kurangnya penyuluhan, fasilitas kesehatan, tenaga medis serta infrastruktur yang kurang memadai dari pemerintah daerah ataupun pusat. Pendekatan dan sentuhan teknologi informasi menjadikan salah satu solusi alternatif yang dilakukan untuk mengeliminasi kesenjangan tersebut, tanpa mengganggu pola dan gaya hidup ibu nifas membutuhkan pelayanan dan edukasi kesehatan pemberian asuhan untuk perawatan selama nifas dan bayi baru lahir yang rutin dan berkualitas (Feroz et al., 2017).

Perawatan bayi baru lahir meliputi perawatan bayi baru lahir yang dapat dilakukan meliputi 


\section{JKM (Jurnal Kebidanan Malahayati),Vol 7,No.4.Oktober 2021, \\ ISSN (Print) 2476-8944 ISSN (Online) 2579-762X, Hal 780-784}

perawatan tali pusar, memandikan bayi, ASI eksklusif, cara memberisihkan hidung, mata, dan telinga bayi, membersihkan kelamin bayi, memoton kuku bayi, menggendong bayi, dan posisi menyusui.Pengetahuan mengenai perawatan bayi baru lahir ini sangat penting karena masa neonatus merupakan masa kritis dalam kehidupan karena transisi adaptasi kehidupan dalam rahim ke kehidupan luar rahim.Pengetahuan ini diterima oleh ibu hamil melaui kelas ibu hamil dan pemanfaatan Buku KIA(Mulyati \& Djamilus, 2017).

Pada masa pandemi covid 19 informasi mengenai perawatan masa nifas dan bayi baru lahir sangat penting, meskipun informasi ini tidak disampaikan langsung kepada ibu hamil tetapi masih bisa menggunakan media digital sebagai sarana pendidikan kesehatan melalui aplikasi nifasku yang dapat di unduh di hp android. Meskipun aplikasi android ini belum terdapat di play store pada saat penelitian link untuk mengunduh aplikasi ini di sebar melalui whatsapp sehingga ibu hamil tetap bisa mengunduh dan menggunakan aplikasi nifasku.

Setelah intervensi diberikan menunjukkan didapatkan peningkatan skor sebelum dan setelah penelitian adalah 12,2 (7,28), $p$ value 0,000 $(a=0,005)$. Sejalan dengan penelitian Fajar Nurhabibi mengemukanan pengetahuan perawatan masa nifas dan bayi baru lahir merupakan hal sangat penting yang harus di ketahui oleh setiap ibu hamil menjelang persalinan, informasi ini penting untuk meningkatkan kualitas ibu paska melahirkan.Peningkatan pengetahuan ini dapat dilakukan dengan cara memberikan pendidikan kesehatan selama kehamilan. Penggunaan metode pendidikan kesehatan yang lebih inovatif di harapakan dapat meng efektifitas pendidikan kesehatan dalam meningkatakan pengetahuan(Nurhabibi, 2018)

Hal ini sesuai dengan penelitian mahbub dkk menerangkan penggunaan telepon seluler secara ekstensif di berbagai negara berkembang menawarkan keunggulan penggunaan mHealth untuk menyebarluaskan informasi kesehatan kepada masyarakat salah satunya untuk meningkatkan kesehtana ibu hamil,nifas perwatan bayi baru lahir.MHealth terbukti dapat meningkatkan pengetahuan dan perilaku positif mengenai kehamilan, perawtan masa nifas dan perewatan kesehatan bayi baru lahir setelah persalianan(Chowdhury, ShibleeS, \& Jones, 2019).

Berdasarkan literature review yang dilakukan oleh Jessica L. Watterson dkk mengemukakan bahwa mHealth dapat memberikan peluang untuk mempengaruhi perubahan perilaku dan memastikan bahwa perempuan dan anak-anak di negara berpenghasilan rendah dapat mengakses pelayanan, termasuk perawatan antenatal, perawatan postnatal, dan imunisasi dan telahditerapkan di negara-negara berpenghasilan rendah dan menengah di seluruh dunia(Watterson, Walsh, \& Madeka, 2015).

Terlepas dari kelebihan aplikasi ini pada Smartphone, masih terlalu dini untuk diterapkan diseluruh lapisan masyarakat Indonesia dan negara-negara berkembang karena kurangnya sumber daya. Tingkatan ekonomi yang luas di Masyarakat membuat aplikasi ini hanya bisa dimanfaatkan pada masyarakat yang memiliki smartphone. Oleh karena itu, penggunaan aplikasi ini dapat dimanfaatkan secara maksimal bagi ibu hamil yang sudah memiliki smart phone sedangkan bagi ibu hamil dengan ekonomi rendah masih sangat diperlukan edukasi konvensional dari tenaga kesehatan untuk mengurangi angka kematian dan kesakitan pada ibu hamil,nifas, bayi baru lahir

\section{SIMPULAN}

Kesimpulan pada penelitian ini terdapat Pengaruh Aplikasi Nifasku terhadap peningkatan pengetahuan pada ibu hamil mengenai tanda bahaya kehamilan setelah diberikan aplikasi sahabat ibu hamil (ASIH).

\section{SARAN}

Aplikasi Nifasku dapat digunakan sebagai media pendidikan kesehatan mengenai informasi persiapan perawatan masa nifas dan bayi baru lahir yang dapat diakses oelh ibu hamil, ibu nifas, bidan.

\section{DAFTAR PUSTAKA}

Astuti, S., Judistiani, tina dewi, Rahmiati, L., \& Susanti, ari indra. (2015). asuhan kebidanan nifas dan menyususi. (R. Astikawati, Ed.) (1st ed.). bandung: Erlangga.

Chowdhury, M. E., ShibleeS, hafayatul I., \& Jones, H. E. (2019). Does mHealth voice messaging work for improving knowledge and practice of maternal and newborn healthcare? BMC Medical Informatics and Decision Making, 212.

Feroz, A., Perveen, S., \& Aftab, W. (2017). Role of mHealth applications for improving antenatal and postnatal care in low and middle income countries : a systematic review, 1-11. https://doi.org/10.1186/s12913-017-2664-7

Ghanylsmaeel, A., \& Khadhm Jabar, E. (2013). Effective System for Pregnant Women using Mobile GIS. International Journal of Computer Applications, 64(11), 1-7. 
https://doi.org/10.5120/10675-5547

Mulyati, S., \& Djamilus, F. (2017). Kelas Ibu Hamil Dan Perilaku Perawtan Bayi. Pendidikan Kesehatan, 6, 43-49.

Norlina, S. (2017). GAMBARAN PENGETAHUAN IBU NIFAS DALAM PERAWATAN NEONATUS DI PUSKESMAS SUNGAI BILU BANJARMASIN TAHUN 2016 ( Overview Of The Pospartum Mother Known In Neonatus Treatment In Sungai Bilu Health Center Banjarmasin Birthday 2016 ), 1(1), 32-35.

Nurhabibi, F. (2018). Pengaruh Pendidikan Kesehatan Tentang Perawatan Nifas
Dengan Metode Take And Give Dalam Meningkatkan Pengetahuan.

SDKI. (2012). Survei Demografi Dan Kesehatan Indonesia. Jakarta: Departemen Kesehatan.

Watterson, J. L., Walsh, J., \& Madeka, I. (2015). Using mHealth to Improve Usage of Antenatal Care, Postnatal Care, and Immunization: A Systematic Review of the Literature. HINDAWI, 9.

WHO. (2015). Pregnancy, Childbirth, Postpartum and Newborn Care. In Pregnancy, Childbirth, Postpartum and Newborn Care (Third Edit). Luxembourg: WHO. 